\title{
A Partial Backlogging Inventory Model for Deteriorating Items with Fluctuating Selling Price and Purchasing Cost
}

\author{
Hui-Ling Yang \\ Department of Computer Science and Information Engineering, Hung Kuang University, \\ 34 Chung-Chie Road, Shalu, Taichung 43302, Taiwan \\ Correspondence should be addressed to Hui-Ling Yang, yanghl@ms19.hinet.net
}

Received 2 October 2011; Revised 12 January 2012; Accepted 14 February 2012

Academic Editor: I. L. Averbakh

Copyright (C) 2012 Hui-Ling Yang. This is an open access article distributed under the Creative Commons Attribution License, which permits unrestricted use, distribution, and reproduction in any medium, provided the original work is properly cited.

\begin{abstract}
In today's competitive markets, selling price and purchasing cost are usually fluctuating with economic conditions. Both selling price and purchasing cost are vital to the profitability of a firm. Therefore, in this paper, I extend the inventory model introduced by Teng and Yang (2004) to allow for not only the selling price but also the purchasing cost to change from one replenishment cycle to another during a finite time horizon. The objective is to find the optimal replenishment schedule and pricing policy to obtain the profit as maximum as possible. The conditions that lead to a maximizing solution guarantee that the existence, uniqueness, and global optimality are proposed. An efficient solution procedure and some theoretical results are presented. Finally, numerical examples for illustration and sensitivity analysis for managerial decision making are also performed.
\end{abstract}

\section{Introduction}

In today's time-based competitive market, the unit selling price of product may increase significantly while its demand increases such as fashionable or valuable goods. On the other hand, the selling prices of items may drop dramatically throughout their life cycles due to advances in technology, competition, and so forth. Thus, the selling price is fluctuating. From the other aspect, some products of the purchasing cost decreases as the demand increases such as the unit cost of a high-tech product declines significantly over its short product life cycle. For example, the cost of a personal computer drops constantly as shown in Lee et al. [1]. Furthermore, the purchasing cost as a percentage of sales is often substantial, which had been mentioned in Heizer and Render [2]. Therefore, from an integrated logistics management perspective, taking the varying selling price and purchasing cost into account is essential. 
Moreover, in reality, for fashionable commodities and high-tech products with short life cycles, the backorder rate is diminishing with the length of waiting time. Customers who experience stock-out will be less likely to buy again from the suppliers, they may turn to another store to purchase the goods. The sales for the product may decline due to the introduction of more competitive product or the change in consumers' preferences. The longer the waiting time, the lower the backlogging rate is. This leads to a larger fraction of lost sales and a less profit. As a result, take the factor of partial backlogging into account is necessary. Abad [3] proposed an optimal pricing and lot-sizing policy under the conditions of perishability and partial backordering. Teng et al. [4] considered the partial backlogging inventory model with time varying demand and purchasing cost. Chang et al. [5] considered the inventory model with selling price and purchasing cost and then provided an optimal replenishment policy for a retailer to achieve its maximum profit. To study the effect of the factors (selling pricing and/or purchasing cost), several authors had developed various models with the related issue. For example, Teng and Yang [6] proposed the inventory lot-size models with time varying demand and purchasing cost under generalized holding cost. Abad [7] added the pricing strategy into consideration and provided the optimal price and lot-size for a retailer when the demand was a function of the selling price. Recently, Sana [8] provided the optimal pricing policy for partial backlogging inventory model with price-dependent demand. Das Roy et al. [9] proposed an optimal shipment strategy for imperfect items in a stock-out situation. Das Roy et al. [10] again provided an economic-order quantity model of imperfect quality items with partial backlogging. The major assumptions and objective used in the above research articles are summarized in Table 1.

Thus, in contrast to the above articles mentioned, the inventory model here is developed as introduced by Teng and Yang [11] to allow for not only selling price but also purchasing cost to be fluctuating, which are changed from one replenishment cycle to another during a finite time horizon. The objective is to find the optimal replenishment schedule and pricing policy to obtain the maximum profit rather than minimum cost. The total profit associated with the inventory system is a concave function of the number of replenishments, which simplifies the search for the optimal number of replenishments to find a local maximum. Moreover, an intuitively estimate for finding the optimal replenishment number is provided. Some numerical examples for illustration and sensitivity analysis for managerial decision making are performed. Finally, summary and suggestions for future research are provided.

\section{Assumptions and Notation}

The mathematical model of the inventory replenishment problem is based on the following assumptions:

(1) The planning horizon of the inventory problem here is finite and is taken as $H$ time units. The initial and the final inventory levels are both zero during the time horizon $H$.

(2) Replenishment is instantaneous and lead time is zero.

(3) In reality, the item may deteriorate with time varying. For simplicity, we assume that the deterioration rate here is constant and there is no repair or replacement of the deteriorated items. 


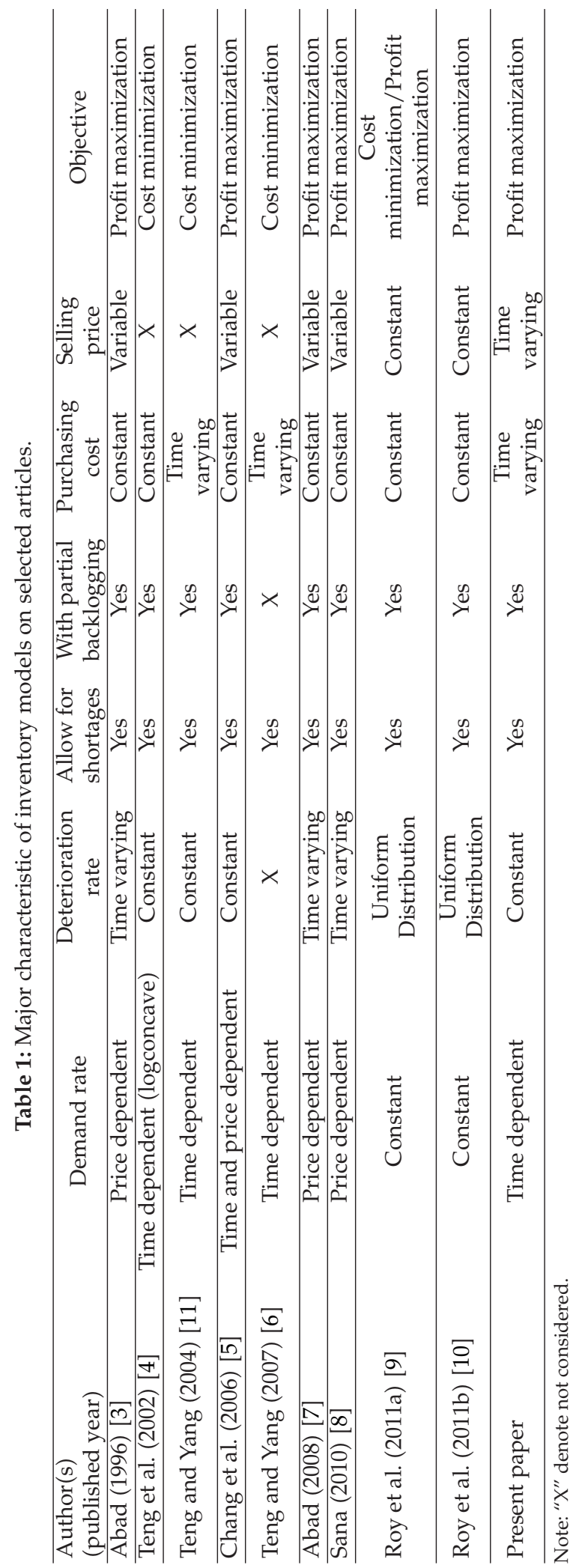


(4) Shortages are allowed. Unsatisfied demand is backlogged, and the fraction of shortages backordered is a decreasing function of time $t$, denoted by $\beta(t)$, where $t$ is the waiting time up to the next replenishment, and $0 \leq \beta(t) \leq 1$ with $\beta(0)=1$. Note that if $\beta(t)=1$ (or 0 ) for all $t$, then shortages are completely backlogged (or lost).

(5) In the lost-sales case, the opportunity cost due to lost sale is the sum of the revenue loss and the cost of lost goodwill. Hence, the opportunity cost due to lost sale here is greater than the unit purchasing cost. For details, see Teng et al. [4].

(6) In today's global high competition environment, we here assume that the selling price and purchasing cost are fluctuating with time and changed from one replenishment cycle to another during a finite time horizon.

For convenience, the following notation is used throughout this paper:

$H$ : the time horizon under consideration,

$f(t)$ : the demand rate at time $t$, without loss of generality, we here assume that $f(t)$ is increase, positive, differentiable in $[0, H]$,

$c_{v}(t)$ : the purchasing cost per unit at time $t$, which is positive, differentiable in $[0, H]$,

$p(t)$ : the selling price per unit at time $t$, which is positive, differentiable in $[0, H]$,

$\theta$ : the deterioration rate,

$c_{f}$ : the fixed ordering cost per order,

$c_{h}$ : the inventory holding cost per unit per unit time,

$c_{b}$ : the backlogging cost per unit per unit time, if the shortage is backlogged,

$c_{l}$ : the unit opportunity cost of lost sales, if the shortage is lost. We assume without loss of generality that $c_{l}>c_{v}(t)$,

$n$ : the number of replenishments over $[0, H]$ (a decision variable),

$t_{i}$ : the $i$ th replenishment time (a decision variable), $i=1,2, \ldots, n$,

$s_{i}$ : the time at which the inventory level reaches zero in the $i$ th replenishment cycle (a decision variable), $i=1,2, \ldots, n$.

\section{Mathematical Model}

For simplicity, we use the same inventory model as in Teng and Yang [11], which is shown in Figure 1.

As a result, we obtain the time-weighted inventory during the $i$ th cycle as

$$
I_{i}=\frac{1}{\theta} \int_{t_{i}}^{s_{i}}\left[e^{\theta\left(t-t_{i}\right)}-1\right] f(t) d t, \quad i=1,2, \ldots, n .
$$

Similarly, the time-weighted backorders due to shortages during the $i$ th cycle is

$$
B_{i}=\int_{s_{i-1}}^{t_{i}}\left(t_{i}-t\right) \beta\left(t_{i}-t\right) f(t) d t, \quad i=1,2, \ldots, n
$$




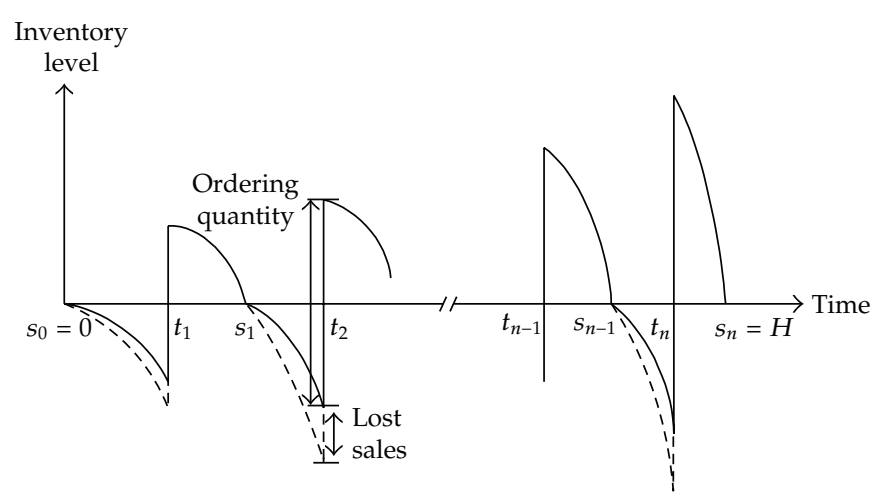

Figure 1: Graphical representation of inventory model.

and the total number of lost sales due to shortages during the $i$ th cycle is

$$
L_{i}=\int_{s_{i-1}}^{t_{i}}\left[1-\beta\left(t_{i}-t\right)\right] f(t) d t, \quad i=1,2, \ldots, n .
$$

The order quantity and unit sold at $t_{i}$ in the $i$ th replenishment cycle is

$$
Q_{i}=\int_{s_{i-1}}^{t_{i}} \beta\left(t_{i}-t\right) f(t) d t+\int_{t_{i}}^{s_{i}} e^{\theta\left(t-t_{i}\right)} f(t) d t, \quad i=1,2, \ldots, n,
$$

and unit sold at $t_{i}$ in the $i$ th replenishment cycle is

$$
S_{i}=\int_{s_{i-1}}^{t_{i}} \beta\left(t_{i}-t\right) f(t) d t+\int_{t_{i}}^{s_{i}} f(t) d t, \quad i=1,2, \ldots, n
$$

Therefore, the purchasing cost during the $i$ th replenishment cycle is

$$
\begin{aligned}
P_{i} & =c_{f}+c_{v}\left(t_{i}\right) Q_{i} \\
& =c_{f}+c_{v}\left(t_{i}\right)\left[\int_{s_{i-1}}^{t_{i}} \beta\left(t_{i}-t\right) f(t) d t+\int_{t_{i}}^{s_{i}} e^{\theta\left(t-t_{i}\right)} f(t) d t\right],
\end{aligned}
$$

and the revenue realized in the $i$ th replenishment cycle is

$$
R_{i}=p\left(t_{i}\right)\left[\int_{s_{i-1}}^{t_{i}} \beta\left(t_{i}-t\right) f(t) d t+\int_{t_{i}}^{s_{i}} f(t) d t\right], \quad i=1,2, \ldots, n .
$$


Hence, if $n$ replenishment orders are placed in $[0, H]$, then the total realized profit of the inventory system during the planning horizon $H$ is

$$
\begin{aligned}
\operatorname{TP}\left(n,\left\{s_{i}\right\},\left\{t_{i}\right\}\right)= & \sum_{i=1}^{n}\left(R_{i}-P_{i}-c_{h} I_{i}-c_{b} B_{i}-c_{l} L_{i}\right) \\
= & \sum_{i=1}^{n} \int_{s_{i-1}}^{t_{i}}\left\{\left[p\left(t_{i}\right)-c_{v}\left(t_{i}\right)-c_{b}\left(t_{i}-t\right)+c_{l}\right] \beta\left(t_{i}-t\right)-c_{l}\right\} f(t) d t-n c_{f} \\
& +\sum_{i=1}^{n} \int_{t_{i}}^{s_{i}}\left[p\left(t_{i}\right)-c_{v}\left(t_{i}\right)-\left(\frac{c_{h}}{\theta}+c_{v}\left(t_{i}\right)\right)\left(e^{\theta\left(t-t_{i}\right)}-1\right)\right] f(t) d t
\end{aligned}
$$

with $0=s_{0}<t_{1}$ and $s_{n}=H$. The problem is to determine $n,\left\{s_{i}\right\}$, and $\left\{t_{i}\right\}$ such that $\operatorname{TP}\left(n,\left\{s_{i}\right\},\left\{t_{i}\right\}\right)$ in (3.8) is maximized.

\section{Theoretical Results and Solution}

For a fixed value of $n$, the necessary conditions for $\operatorname{TP}\left(n,\left\{s_{i}\right\},\left\{t_{i}\right\}\right)$ to be maximized are: $\partial T P\left(n,\left\{s_{i}\right\},\left\{t_{i}\right\}\right) / \partial t_{i}=0$ for $i=1,2, \ldots, n$, and $\partial T P\left(n,\left\{s_{i}\right\},\left\{t_{i}\right\}\right) / \partial s_{i}=0$, for. $i=1,2, \ldots, n-1$. Consequently, we obtain

$$
\begin{aligned}
& \int_{t_{i}}^{s_{i}}\left\{p^{\prime}\left(t_{i}\right)+\left[c_{h}+\theta c_{v}\left(t_{i}\right)-c_{v}^{\prime}\left(t_{i}\right)\right] e^{\theta\left(t-t_{i}\right)}\right\} f(t) d t \\
& \quad=-\int_{s_{i-1}}^{t_{i}}\left\{\left[p^{\prime}\left(t_{i}\right)-c_{v}^{\prime}\left(t_{i}\right)-c_{b}\right] \beta\left(t_{i}-t\right)+\left[p\left(t_{i}\right)+c_{l}-c_{v}\left(t_{i}\right)-c_{b}\left(t_{i}-t\right)\right] \beta^{\prime}\left(t_{i}-t\right)\right\} f(t) d t \\
& {\left[p\left(t_{i+1}\right)-c_{v}\left(t_{i+1}\right)-c_{b}\left(t_{i+1}-s_{i}\right)\right] \beta\left(t_{i+1}-s_{i}\right)-c_{l}\left[1-\beta\left(t_{i+1}-s_{i}\right)\right]} \\
& \quad=p\left(t_{i}\right)-c_{v}\left(t_{i}\right)-\left[\frac{c_{h}}{\theta}+c_{v}\left(t_{i}\right)\right]\left(e^{\theta\left(s_{i}-t_{i}\right)}-1\right)
\end{aligned}
$$

respectively. Note that (4.1) and (4.2) are coincident with the following articles'

(1) Equations (12) and (11) in Teng and Yang [11], if $p(t)=0$,

(2) Equations (15) and (14) in Teng et al. [4], if $p(t)=0$ and $c_{v}(t)=c_{v}$,

(3) Equations (11) and (10) in Chang et al. [5], if $p(t)=p$ and $c_{v}(t)=c_{v}$.

Thus, the model here proposed is a generalization of the above three mentioned models. For simplicity, from (4.2), let the marginal resultant profit per unit during noshortage and shortage period be

$$
R(t, u)=p(t)-c_{v}(t)-\left[\frac{c_{h}}{\theta}+c_{v}(t)\right]\left(e^{\theta(u-t)}-1\right)
$$

with $t \leq u$, and

$$
P(s, t)=\left[p(t)-c_{v}(t)-c_{b}(t-s)\right] \beta(t-s)-c_{l}[1-\beta(t-s)]
$$


with $s \leq t$, respectively. Taking the partial derivative of $R(t, u)$ and $P(s, t)$ with respect to $t$ respectively, we obtained the following results:

$$
\begin{gathered}
R_{t}(t, u)=p^{\prime}(t)+\left[c_{h}+\theta c_{v}(t)-c_{v}^{\prime}(t)\right] e^{\theta(u-t)}, \\
P_{t}(s, t)=\left[p^{\prime}(t)-c_{v}^{\prime}(t)-c_{b}\right] \beta(t-s)+\left[p(t)+c_{l}-c_{v}(t)-c_{b}(t-s)\right] \beta^{\prime}(t-s) .
\end{gathered}
$$

Note that the longer the waiting time, the lower the marginal resultant profit. Consequently, $P(s, t)$ is a decreasing function of $t$. Thus, we may assume without loss of generality that $P_{t}(s, t)<0$, for all $t>s$. Then, we obtain the following result.

Lemma 4.1. For any given $n$, if $R_{t_{i}}\left(t_{i}, t\right) \leq 0$, with $t \geq t_{i}$, and $P_{t_{i}}\left(t, t_{i}\right)<0$, with $t \leq t_{i}$, $i=$ $1,2, \ldots, n$, then the optimal solution is $n^{*}=1$ and $t_{1}^{*}=0$ (i.e., purchase at the beginning).

Proof. See Appendix A.

The results in Lemma 4.1 can be interpreted as follows. The condition $R_{t_{i}}\left(t_{i}, t\right) \leq 0$ implies that $p^{\prime}(t)+\left[c_{h}+\theta c_{v}(t)\right] e^{\theta(u-t)} \leq c_{v}^{\prime}(t) e^{\theta(u-t)}$. This means that the increasing rate of the unit purchasing cost is higher than or equal to the sum of the marginal selling price and marginal inventory carrying cost per unit (which includes inventory and deterioration costs). Therefore, buying and storing a unit and then selling now are more profitable than buying and selling it later.

Theorem 4.2. For any given $n$, if $R_{t_{i}}\left(t_{i}, t\right)>0$, with $t \geq t_{i}$, and $P_{t_{i}}\left(t, t_{i}\right)<0$, with $t \leq t_{i}, i=$ $1,2, \ldots, n$, then the solution that satisfies the system of (4.1) and (4.2) exists uniquely and $0 \leq s_{i-1}<$ $t_{i}<s_{i}$, for $i=1,2, \ldots, n$.

Proof. See Appendix B.

The result in Theorem 4.2 reduces the $2 n$-dimensional problem of finding $\left\{s_{i}^{*}\right\}$ and $\left\{t_{i}^{*}\right\}$ to a one-dimensional problem. Since $s_{0}=0$, we only need to find $t_{1}^{*}$ to generate $s_{1}^{*}$ by (4.1), $t_{2}^{*}$ by (4.2), and then the rest of $\left\{s_{i}^{*}\right\}$ and $\left\{t_{i}^{*}\right\}$ uniquely by repeatedly using (4.1) and (4.2). For any chosen $t_{1}^{*}$, if $s_{n}^{*}=H$, then $t_{1}^{*}$ is chosen correctly. Otherwise, we can easily find the optimal $t_{1}^{*}$ by standard search techniques.

Having calculated the second partial derivatives of the function $\operatorname{TP}\left(n,\left\{s_{i}\right\},\left\{t_{i}\right\}\right)$ shows that the Hessian matrix is negative definite if

$$
\begin{aligned}
& \frac{\partial^{2} T P}{\partial t_{i}^{2}} \leq-\left[\frac{\partial^{2} T P}{\partial s_{i} \partial t_{i}}+\frac{\partial^{2} T P}{\partial t_{i} \partial s_{i-1}}\right]<0, \quad \text { for } i=1,2, \ldots, n, \\
& \frac{\partial^{2} T P}{\partial s_{i}^{2}} \leq-\left[\frac{\partial^{2} T P}{\partial s_{i} \partial t_{i}}+\frac{\partial^{2} T P}{\partial t_{i+1} \partial s_{i}}\right]<0, \quad \text { for } i=1,2, \ldots, n .
\end{aligned}
$$

Theorem 4.3. For any given $n$, if $R_{t_{i}}\left(t_{i}, t\right)>0$, with $t \geq t_{i}$, and $P_{t_{i}}\left(t, t_{i}\right)<0$, with $t \leq t_{i}, i=$ $1,2, \ldots, n$, under conditions (4.7)-(4.8), then the solution that satisfies the system of (4.1) and (4.2) is a global maximum solution.

Proof. See Appendix C. 
Next, we show that the total profit $T P\left(n,\left\{s_{i}^{*}\right\},\left\{t_{i}^{*}\right\}\right)$ is a concave function of the number of replenishments. As a result, the search for the optimal replenishment number, $n^{*}$, is reduced to find a local maximum. For simplicity, let

$$
T P(n)=P\left(n,\left\{s_{i}^{*}\right\},\left\{t_{i}^{*}\right\}\right)
$$

By applying Bellman's principle of optimality [12], we have the following theorem:

Theorem 4.4. $T P(n)$ is concave in $n$.

Proof. The proof is similar to that of Teng and Yang [11], the reader can easily prove it.

By a similar discussion as in Teng and Yang [11], I here use the average backlogging rate $\bar{\beta}$, unit purchasing cost $\overline{c_{v}}$ and average unit selling price $\bar{p}$ to replace $\beta\left(t_{i+1}-s_{i}\right), c_{v}\left(t_{i}\right)$ and $p\left(t_{i}\right)$, respectively. the estimate of the number of replenishments is obtained as

$$
n_{1}=\text { rounded integer of }\left[\frac{\left(c_{h}+\theta \overline{c_{v}}\right)\left[c_{b} \bar{\beta}+\left(c_{l}-\overline{c_{v}}+\bar{p}\right)(1-\bar{\beta})\right] H Q(H)}{2 c_{f}\left[c_{h}+\theta \overline{c_{v}}+c_{b} \bar{\beta}+\left(c_{l}-\overline{c_{v}}+\bar{p}\right)(1-\bar{\beta})\right]}\right]^{1 / 2} \text {, }
$$

where $Q(H)=\int_{0}^{H} f(t) d t$. It is obvious that searching for $n^{*}$ by starting with $n$ in (4.10) will speed the computational efficiency significantly, comparing to starting with $n=1$. The algorithm for determining the optimal number of replenishments $n^{*}$ and schedule is summarized as follows.

\section{Algorithm for Finding Optimal Number and Schedule}

Step 1. Choose two initial trial values of $n^{*}$, say $n$ as in (4.10) and $n-1$. Use a standard search method to obtain $\left\{t_{i}^{*}\right\}$ and $\left\{s_{i}^{*}\right\}$, and compute the corresponding $T P(n)$ and $T P(n-1)$, respectively.

Step 2. If $T P(n) \geq T P(n-1)$, then compute $T P(n+1), T P(n+2), \ldots$, until we find $T P(k)>$ $T P(k+1)$. Set $n^{*}=k$ and stop.

Step 3. If $T P(n)<T P(n-1)$, then compute $T P(n-2), T P(n-3), \ldots$, until we find $T P(k)>$ $T P(k-1)$. Set $n^{*}=k$ and stop.

\section{Numerical Examples}

Example 5.1. Let $f(t)=200+20 t, H=3, p(t)=200+30 t, c_{v}(t)=150+10 t, c_{f}=250, c_{h}=40$, $c_{b}=50, c_{l}=200, \theta=0.08, \beta(t)=e^{-0.4 t}$ in appropriate units. After calculation, we have $\bar{p}=245, \bar{c}_{v}=165$, and $\bar{\beta}=0.582$. By (4.10), we obtain the estimate number of replenishments $n_{1}=12$. From computational results, we have $T P(13)=49021.79, T P(14)=49044.31$, and $T P(15)=49030.61$. Therefore, the optimal number of replenishments is 14 , and the optimal profit is 49044.31. The optimal replenishment schedule is shown in Table 2. 
Table 2: The optimal replenishment schedule for Example 5.1.

\begin{tabular}{lccccccc}
\hline$i$ & 1 & 2 & 3 & 4 & 5 & 6 & 7 \\
\hline$t_{i}$ & 0.0849 & 0.3160 & 0.5437 & 0.7683 & 0.9899 & 1.2086 & 1.4245 \\
$s_{i}$ & 0.2330 & 0.4626 & 0.6889 & 0.9121 & 1.1323 & 1.3497 & 1.5644 \\
$p\left(t_{i}\right)$ & 202.55 & 209.48 & 216.31 & 223.05 & 229.70 & 236.26 & 242.73 \\
$c_{v}\left(t_{i}\right)$ & 150.85 & 153.16 & 155.44 & 157.68 & 159.90 & 162.09 & 164.24 \\
\hline$i$ & 8 & 9 & 10 & 11 & 12 & 13 & 14 \\
\hline$t_{i}$ & 1.6378 & 1.8485 & 2.0569 & 2.2629 & 2.4666 & 2.6682 & 2.8676 \\
$s_{i}$ & 1.7765 & 1.9861 & 2.1933 & 2.3982 & 2.6009 & 2.8015 & 3.0000 \\
$p\left(t_{i}\right)$ & 249.13 & 255.46 & 261.71 & 267.89 & 274.00 & 280.05 & 286.03 \\
$c_{v}\left(t_{i}\right)$ & 166.38 & 168.49 & 170.57 & 172.63 & 174.67 & 176.68 & 178.68 \\
\hline
\end{tabular}

Table 3: Sensitivity analysis on parameters changed for Example 5.2.

\begin{tabular}{lcccccc}
\hline Parameter Parameter value & $\begin{array}{c}\text { \% change in } \\
\text { parameter }\end{array}$ & Estimated $n_{1}$ & Optimal $n^{*}$ & $T P^{*}\left(n^{*}\right)$ & $\begin{array}{c}\text { \% change in } \\
T P^{*}\left(n^{*}\right)\end{array}$ \\
\hline \multirow{2}{*}{$c_{f}$} & 200 & -20 & 14 & 16 & 49787.47 & 1.52 \\
& 300 & +20 & 11 & 13 & 48371.79 & -1.37 \\
\hline \multirow{2}{*}{$c_{h}$} & 30 & -25 & 12 & 13 & 49379.80 & 0.68 \\
& 50 & +25 & 13 & 15 & 48748.20 & -0.60 \\
$c_{b}$ & 40 & -20 & 12 & 14 & 49135.56 & 0.19 \\
& 60 & +20 & 13 & 14 & 48961.05 & -0.17 \\
$c_{l}$ & 150 & -25 & 12 & 14 & 49238.33 & 0.40 \\
\hline \multirow{2}{*}{$\theta$} & 250 & +25 & 13 & 14 & 48883.42 & -0.33 \\
\hline \multirow{2}{*}{$\beta(t)$} & 0.06 & -25 & 12 & 14 & 49152.16 & 0.22 \\
& 0.1 & +25 & 13 & 14 & 48939.71 & -0.21 \\
\hline
\end{tabular}

Example 5.2. To understand the effect of changes in parameters $c_{f}, c_{h}, c_{b}, c_{l}, \theta, \beta(t)$ on the optimal solution, the sensitivity analysis is performed by changing one parameter at a time and keeps the others unchanged. The parameter values are the same as in Example 5.1. The results obtained are shown as in Table 3.

From Table 3, the following phenomena can be obtained.

(1) The optimal maximum profit decreases as $c_{f}, c_{h}, c_{b}, c_{l}, \theta$ increases, however, it increases as the backlogging rate $\beta(t)$ increases.

(2) The optimal maximum profit is more sensitive on parameters $c_{f}$ than others.

(3) The optimal replenishment number is very slightly sensitive to the change of these parameters except $c_{f}$ and $\beta(t)$.

(4) The estimated number $n_{1}$ is very close to the optimal replenishment number $n^{*}$, no matter what magnitude of the parameters changed.

Example 5.3. Using the same numerical values as in Example 5.1, we consider the influence of changes of the rate of change of selling price $p(t)$ and purchasing $\operatorname{cost} c_{v}(t)$ on the total profit. The results are obtained as shown in Table 4. 
Table 4: Sensitivity analysis on rate of change for Example 5.3.

\begin{tabular}{|c|c|c|c|c|c|}
\hline$p(t), c_{v}(t)$ & $\begin{array}{l}\% \text { change in rate } \\
\text { of change }\end{array}$ & Estimated $n_{1}$ & Optimal $n^{*}$ & $T P^{*}\left(n^{*}\right)$ & $\begin{array}{c}\% \text { change in } \\
T P^{*}\left(n^{*}\right)\end{array}$ \\
\hline$p(t)=200+30 t$ & - & \multirow[t]{2}{*}{12} & \multirow[t]{2}{*}{14} & \multirow[t]{2}{*}{49044.31} & \multirow[t]{2}{*}{0.00} \\
\hline$c_{v}(t)=150+10 t$ & - & & & & \\
\hline$p(t)=200+45 t$ & +50 & \multirow[t]{2}{*}{13} & \multirow[t]{2}{*}{15} & \multirow{2}{*}{64887.92} & \multirow[t]{2}{*}{32.30} \\
\hline$c_{v}(t)=150+10 t$ & - & & & & \\
\hline$p(t)=200+15 t$ & -50 & \multirow{2}{*}{12} & \multirow{2}{*}{14} & \multirow{2}{*}{33314.34} & \multirow{2}{*}{-32.07} \\
\hline$c_{v}(t)=150+10 t$ & - & & & & \\
\hline$p(t)=200+30 t$ & - & \multirow{2}{*}{12} & \multirow{2}{*}{14} & \multirow{2}{*}{43768.8} & \multirow{2}{*}{-10.76} \\
\hline$c_{v}(t)=150+15 t$ & +50 & & & & \\
\hline$p(t)=200+30 t$ & - & \multirow[t]{2}{*}{12} & \multirow{2}{*}{14} & \multirow{2}{*}{54329.55} & \multirow{2}{*}{10.78} \\
\hline$c_{v}(t)=150+5 t$ & -50 & & & & \\
\hline
\end{tabular}

From Table 4, it is obviously that the phenomena are obtained.

(1) The percentage change in total maximum profit is significantly sensitive on the variation of rate of change.

(2) The total profit increases as the rate of change of selling price increases, while decreases as the rate of change of purchasing cost increases.

(3) The estimated number $n_{1}$ is also close to the optimal replenishment number $n^{*}$.

(4) The optimal replenishment number is slightly sensitive to the change of rate of change.

\section{Conclusions}

In this paper, a partial-backlogging inventory lot-size model for deteriorating items with time dependent demand, fluctuating selling price and purchasing cost is considered. We show that the optimal replenishment schedule exists uniquely and the total profit associated with the inventory system is a concave function of the number of replenishments. An intuitively estimate for finding the optimal replenishment number is provided. From the sensitivity analysis, the results indicate that the effect of variation of rate of change of the selling price and purchasing cost on the system behavior is significant. Thus, to incorporate the selling price and purchasing cost into the inventory model is vital, especially in the present changeable market.

With more practical features, the model developed here can be further extended by incorporating with other kind of functions or parameters, such as considering the demand as a function of selling price or stock dependent, or time varying deterioration rate, or to develop the model by employing other factors, such as inflation and price discount. 


\section{Appendices}

\section{A. Proof of Lemma 4.1}

Let

$$
\begin{aligned}
T P_{i}\left(s_{i-1}, t_{i}, s_{i}\right)= & \int_{s_{i-1}}^{t_{i}}\left\{\left[p\left(t_{i}\right)-c_{v}\left(t_{i}\right)-c_{b}\left(t_{i}-t\right)+c_{l}\right] \beta\left(t_{i}-t\right)-c_{l}\right\} f(t) d t \\
& +\int_{t_{i}}^{s_{i}}\left\{p\left(t_{i}\right)-c_{v}\left(t_{i}\right)-\left[\frac{c_{h}}{\theta}+c_{v}\left(t_{i}\right)\right]\left(e^{\theta\left(t-t_{i}\right)}-1\right)\right\} f(t) d t \\
= & \int_{s_{i-1}}^{t_{i}} P\left(t, t_{i}\right) f(t) d t+\int_{t_{i}}^{s_{i}} R\left(t_{i}, t\right) f(t) d t .
\end{aligned}
$$

We then have

$$
\frac{\partial T P_{i}}{\partial t_{i}}=\int_{s_{i-1}}^{t_{i}} P_{t_{i}}\left(t, t_{i}\right) f(t) d t+\int_{t_{i}}^{s_{i}} R_{t_{i}}\left(t_{i}, t\right) f(t) d t
$$

If $R_{t_{i}}\left(t_{i}, t\right) \leq 0$, then we know from (A.2) that $\partial T P_{i} / \partial t_{i} \leq 0$. Therefore, for any given $i$, $T P_{i}$ is decreasing with $t_{i}$. This implies that $T P_{i}\left(s_{i-1}, s_{i-1}, s_{i}\right) \geq T P_{i}\left(s_{i-1}, t_{i}, s_{i}\right)$ for any fixed $i$. Consequently, we obtain

$$
\begin{aligned}
T P\left(n,\left\{s_{i}\right\},\left\{t_{i}\right\}\right) & =\sum_{i=1}^{n} T P_{i}\left(s_{i-1}, t_{i}, s_{i}\right)-n c_{f} \\
& \leq \sum_{i=1}^{n} T P_{i}\left(s_{i-1}, s_{i-1}, s_{i}\right)-n c_{f}=\sum_{i=1}^{n} \int_{s_{i-1}}^{s_{i}} R\left(s_{i-1}, t\right) f(t) d t-n c_{f} \\
& \left.\leq \sum_{i=1}^{n} \int_{s_{i-1}}^{s_{i}} R(0, t) f(t) d t-n c_{f} \quad \text { (since } R_{t_{i}}\left(t_{i}, t\right) \leq 0\right) \\
& \leq \int_{0}^{H} R(0, t) f(t) d t-c_{f} .
\end{aligned}
$$

This completes the proof.

\section{B. Proof of Theorem 4.2}

For any given $s_{i-1}$ and $t_{i}$, from (4.1), we set

$$
\begin{aligned}
F(x)= & \int_{t_{i}}^{x}\left\{p^{\prime}\left(t_{i}\right)+\left[c_{h}+\theta c_{v}\left(t_{i}\right)-c_{v}^{\prime}\left(t_{i}\right)\right] e^{\theta\left(t-t_{i}\right)}\right\} f(t) d t \\
& +\int_{s_{i-1}}^{t_{i}}\left\{\left[p^{\prime}\left(t_{i}\right)-c_{v}^{\prime}\left(t_{i}\right)-c_{b}\right] \beta\left(t_{i}-t\right)+\left[p\left(t_{i}\right)+c_{l}-c_{v}\left(t_{i}\right)-c_{b}\left(t_{i}-t\right)\right] \beta^{\prime}\left(t_{i}-t\right)\right\} f(t) d t \\
= & \int_{t_{i}}^{x} R_{t_{i}}\left(t_{i}, t\right) f(t) d t+\int_{s_{i-1}}^{t_{i}} P_{t_{i}}\left(t, t_{i}\right) f(t) d t, \quad \text { with } x \geq t_{i} \geq s_{i-1} .
\end{aligned}
$$


We then have

$$
F\left(t_{i}\right)=\int_{s_{i-1}}^{t_{i}} P_{t_{i}}\left(t, t_{i}\right) f(t) d t<0,
$$

and $\lim _{x \rightarrow \infty} F(x)>0$. Taking the first derivatives of $F(x)$ with respect to $x$, we obtain

$$
F^{\prime}(x)=R_{t_{i}}\left(t_{i}, x\right) f(x)>0 .
$$

As a result, we know that there exists a unique $s_{i}\left(>t_{i}\right)$ such that $F\left(s_{i}\right)=0$. Thus, the solution to (4.1) uniquely exists. Similarly, from (4.2), we set

$$
\begin{aligned}
G(x)= & {\left[p(x)-c_{v}(x)-c_{b}\left(x-s_{i}\right)+c_{l}\right] \beta\left(x-s_{i}\right)-\left[p\left(t_{i}\right)-c_{v}\left(t_{i}\right)+c_{l}\right] } \\
& +\left[\frac{c_{h}}{\theta}+c_{v}\left(t_{i}\right)\right]\left(e^{\theta\left(s_{i}-t_{i}\right)}-1\right)=P\left(s_{i}, x\right)-R\left(t_{i}, s_{i}\right), \quad \text { with } x \geq s_{i} \geq t_{i} .
\end{aligned}
$$

We then have

$$
G\left(s_{i}\right)=p\left(s_{i}\right)-c_{v}\left(s_{i}\right)-R\left(t_{i}, s_{i}\right)=R\left(s_{i}, s_{i}\right)-R\left(t_{i}, s_{i}\right)>0,
$$

since $R_{t_{i}}\left(t_{i}, t\right)>0$, and $\lim _{x \rightarrow \infty} G(x)=-c_{l}<0$. By taking the first derivatives of $G(x)$ with respect to $x$, we obtain

$$
G^{\prime}(x)=P_{x}\left(s_{i}, x\right)<0 .
$$

Consequently, there exists a unique $t_{i+1}\left(>s_{i}\right)$ such that $G\left(t_{i+1}\right)=0$, which implies that solution to (4.2) uniquely exists. Therefore, we complete the proof.

\section{Proof of Theorem 4.3}

Taking the second derivatives with respect to $t_{i}$ and $s_{i}$ on $\operatorname{TP}\left(n,\left\{s_{i}\right\},\left\{t_{i}\right\}\right)$, we have

$$
\begin{aligned}
\frac{\partial^{2} T P}{\partial t_{i}^{2}}= & {\left[\left(p\left(t_{i}\right)+c_{l}-c_{v}\left(t_{i}\right)\right) \beta^{\prime}(0)-c_{h}-\theta c_{v}\left(t_{i}\right)-c_{b}\right] f\left(t_{i}\right) } \\
& +\int_{s_{i-1}}^{t_{i}}\left\{\left[p^{\prime \prime}\left(t_{i}\right)-c_{v}^{\prime \prime}\left(t_{i}\right)\right] \beta\left(t_{i}-t\right)+2\left[p^{\prime}\left(t_{i}\right)-c_{v}^{\prime}\left(t_{i}\right)-c_{b}\right] \beta^{\prime}\left(t_{i}-t\right)\right. \\
& \left.+\left[p\left(t_{i}\right)+c_{l}-c_{v}\left(t_{i}\right)-c_{b}\left(t_{i}-t\right)\right] \beta^{\prime \prime}\left(t_{i}-t\right)\right\} f(t) d t
\end{aligned}
$$




$$
\begin{aligned}
& +\int_{t_{i}}^{s_{i}}\left\{p^{\prime \prime}\left(t_{i}\right)+\left[\theta c_{v}^{\prime}\left(t_{i}\right)-c_{v}^{\prime \prime}\left(t_{i}\right)-\theta\left(c_{h}+\theta c_{v}\left(t_{i}\right)-c_{v}^{\prime}\left(t_{i}\right)\right)\right] e^{\theta\left(t-t_{i}\right)}\right\} f(t) d t, \\
\frac{\partial^{2} T P}{\partial s_{i-1} \partial t_{i}}= & -P_{t_{i}}\left(s_{i-1}, t_{i}\right) f\left(s_{i-1}\right)>0 \\
\frac{\partial^{2} T P}{\partial t_{i} \partial s_{i}}= & R_{t_{i}}\left(t_{i}, s_{i}\right) f\left(s_{i}\right)>0 \\
\frac{\partial^{2} T P}{\partial s_{i}^{2}}= & \left\{\left[p\left(t_{i+1}\right)+c_{l}-c_{v}\left(t_{i+1}\right)-c_{b}\left(t_{i+1}-s_{i}\right)\right] \beta^{\prime}\left(t_{i+1}-s_{i}\right)-c_{b} \beta\left(t_{i+1}-s_{i}\right)\right. \\
& \left.-\left[c_{h}+\theta c_{v}\left(t_{i}\right)\right] e^{\theta\left(s_{i}-t_{i}\right)}\right\} f\left(s_{i}\right) .
\end{aligned}
$$

Let $\Delta_{k}$ be the principal minor of order $k$, then, under condition (4.7)-(4.8), it is clear that

$$
\Delta_{1}=\frac{\partial^{2} T P}{\partial t_{1}^{2}} \leq-\frac{\partial^{2} T P}{\partial s_{1} \partial t_{1}}=-R_{t_{1}}\left(t_{1}, s_{1}\right) f\left(s_{1}\right)<0
$$

which implies that $\Delta_{1}+\left(\partial^{2} T P / \partial s_{1} \partial t_{1}\right)<0$ :

$$
\Delta_{2}=\frac{\partial^{2} T P}{\partial t_{1}^{2}} \frac{\partial^{2} T P}{\partial s_{1}^{2}}-\frac{\partial^{2} T P}{\partial s_{1} \partial t_{1}} \frac{\partial^{2} T P}{\partial t_{1} \partial s_{1}} \geq-\frac{\partial^{2} T P}{\partial t_{2} \partial s_{1}} \Delta_{1}-\frac{\partial^{2} T P}{\partial t_{1} \partial s_{1}}\left(\Delta_{1}+\frac{\partial^{2} T P}{\partial t_{1} \partial s_{1}}\right)>0
$$

which implies that $\Delta_{2}+\left(\partial^{2} T P / \partial t_{2} \partial s_{1}\right) \Delta_{1}>0$. For principal minor of higher order, $i=2,3, \ldots$, it is not difficult to show that they satisfy the following recursive relation:

$$
\begin{aligned}
\Delta_{2 i-1} & =\frac{\partial^{2} T P}{\partial t_{i}^{2}} \Delta_{2 i-2}-\left[\frac{\partial^{2} T P}{\partial t_{i} \partial s_{i-1}}\right]^{2} \Delta_{2 i-3}, \\
\Delta_{2 i} & =\frac{\partial^{2} T P}{\partial s_{i}^{2}} \Delta_{2 i-1}-\left[\frac{\partial^{2} T P}{\partial s_{i} \partial t_{i}}\right]^{2} \Delta_{2 i-2,}
\end{aligned}
$$

with the initial $\Delta_{0}=1$. From (4.7)-(4.8) and the relation between second-order partial derivatives, we have

$$
\begin{aligned}
\Delta_{2 i-1} & \leq-\frac{\partial^{2} T P}{\partial s_{i} \partial t_{i}} \Delta_{2 i-2}-\frac{\partial^{2} T P}{\partial t_{i} \partial s_{i-1}}\left(\Delta_{2 i-2}+\frac{\partial^{2} T P}{\partial t_{i} \partial s_{i-1}} \Delta_{2 i-3}\right), \\
\Delta_{2 i} & \geq-\frac{\partial^{2} T P}{\partial t_{i+1} \partial s_{i}} \Delta_{2 i-1}-\frac{\partial^{2} T P}{\partial s_{i} \partial t_{i}}\left(\Delta_{2 i-1}+\frac{\partial^{2} T P}{\partial s_{i} \partial t_{i}} \Delta_{2 i-2}\right) .
\end{aligned}
$$


For $i=2$ in (C.5), we obtain

$$
\begin{aligned}
& \Delta_{3}+\frac{\partial^{2} T P}{\partial s_{2} \partial t_{2}} \Delta_{2} \leq-\frac{\partial^{2} T P}{\partial t_{2} \partial s_{1}}\left(\Delta_{2}+\frac{\partial^{2} T P}{\partial t_{2} \partial s_{1}} \Delta_{1}\right)<0 \\
& \Delta_{4}+\frac{\partial^{2} T P}{\partial t_{3} \partial s_{2}} \Delta_{3} \geq-\frac{\partial^{2} T P}{\partial s_{2} \partial t_{2}}\left(\Delta_{3}+\frac{\partial^{2} T P}{\partial s_{2} \partial t_{2}} \Delta_{2}\right)>0 .
\end{aligned}
$$

Thus,

$$
\Delta_{3}<-\frac{\partial^{2} T P}{\partial s_{2} \partial t_{2}} \Delta_{2}<0, \quad \Delta_{4}>-\frac{\partial^{2} T P}{\partial t_{3} \partial s_{2}} \Delta_{3}>0
$$

Proceeding inductively, we have

$$
\Delta_{2 i-1}+\frac{\partial^{2} T P}{\partial s_{i} \partial t_{i}} \Delta_{2 i-2}<0, \quad \Delta_{2 i}+\frac{\partial^{2} T P}{\partial t_{i+1} \partial s_{i}} \Delta_{2 i-1}>0
$$

Therefore, $\Delta_{2 i-1}<0$ and $\Delta_{2 i}>0$, for $i=2,3, \ldots$ This completes the proof.

\section{Acknowledgments}

The author would like to thank the editor and anonymous reviewers for their valuable and constructive comments which have led to a significant improvement in the manuscript. This research was supported by the National Science Council of the Republic of China under Grant NSC 96-2221-E-241-001.

\section{References}

[1] H. L. Lee, V. Padmanabhan, T. A. Taylor, and S. Whang, "Price protection in the personal computer industry," Management Science, vol. 46, no. 4, pp. 467-482, 2000.

[2] J. Heizer and B. Render, Operations Management, Prentice-Hall, Upper Saddle River, NJ, USA, 6th edition, 2000.

[3] P. L. Abad, "Optimal pricing and lot-sizing under conditions of perishability and partial backordering," Management Science, vol. 42, no. 8, pp. 1093-1104, 1996.

[4] J.-T. Teng, H.-J. Chang, C.-Y. Dye, and C.-H. Hung, "An optimal replenishment policy for deteriorating items with time-varying demand and partial backlogging," Operations Research Letters, vol. 30, no. 6, pp. 387-393, 2002.

[5] H.-J. Chang, J.-T. Teng, L.-Y. Ouyang, and C.-Y. Dye, “Retailer's optimal pricing and lot-sizing policies for deteriorating items with partial backlogging," European Journal of Operational Research, vol. 168, no. 1, pp. 51-64, 2006.

[6] J.-T. Teng and H.-L. Yang, "Deterministic inventory lot-size models with time-varying demand and cost under generalized holding costs," International Journal of Information and Management Sciences, vol. 18, no. 2, pp. 113-125, 2007.

[7] P. L. Abad, "Optimal price and order size under partial backordering incorporating shortage, backorder and lost sale costs," International Journal of Production Economics, vol. 114, no. 1, pp. 179 186, 2008.

[8] S. S. Sana, "Optimal selling price and lotsize with time varying deterioration and partial backlogging," Applied Mathematics and Computation, vol. 217, no. 1, pp. 185-194, 2010. 
[9] M. Das Roy, S. S. Sana, and K. Chaudhuri, "An optimal shipment strategy for imperfect items in a stock-out situation," Mathematical and Computer Modelling, vol. 54, no. 9-10, pp. 2528-2543, 2011.

[10] M. Das Roy, S. S. Sana, and K. Chaudhuri, "An economic order quantity model of imperfect quality items with partial backlogging," International Journal of Systems Science. Principles and Applications of Systems and Integration, vol. 42, no. 8, pp. 1409-1419, 2011.

[11] J. T. Teng and H. L. Yang, "Deterministic economic order quantity models with partial backlogging when demand and cost are fluctuating with time," Journal of the Operational Research Society, vol. 55, no. 5, pp. 495-503, 2004.

[12] R. Bellman, Dynamic Programming, Princeton University Press, Princeton, NJ, USA, 1957. 


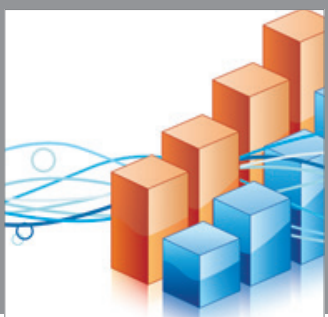

Advances in

Operations Research

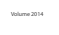

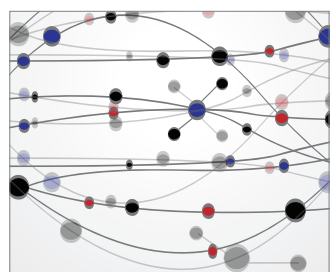

\section{The Scientific} World Journal
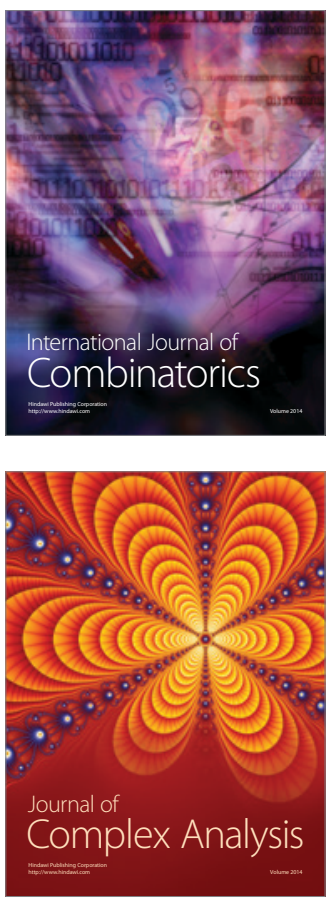

International Journal of

Mathematics and

Mathematical

Sciences
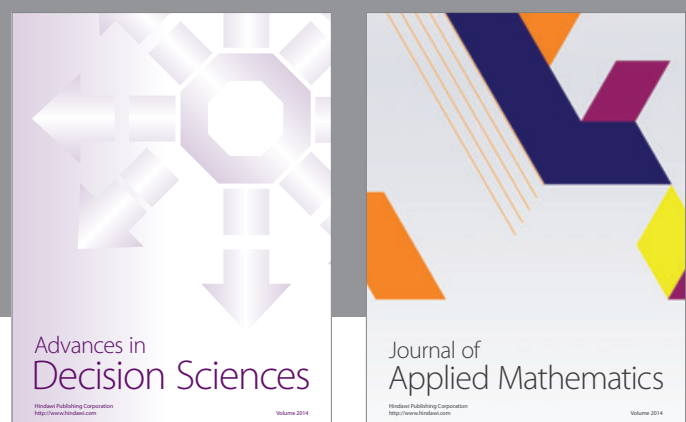

Journal of

Applied Mathematics
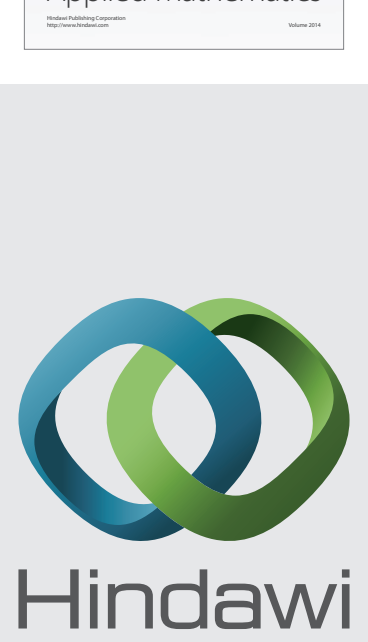

Submit your manuscripts at http://www.hindawi.com
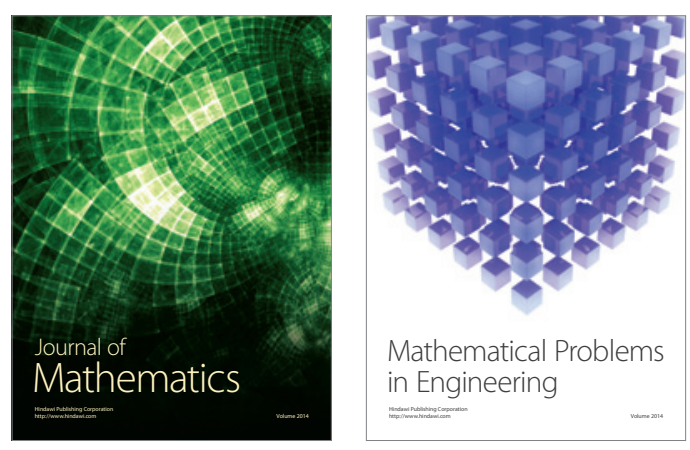

Mathematical Problems in Engineering
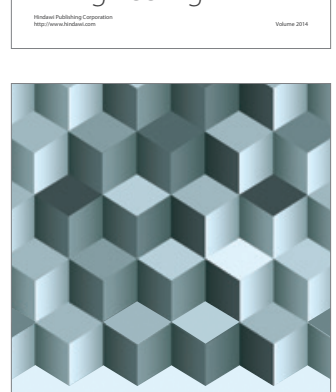

Journal of

Function Spaces
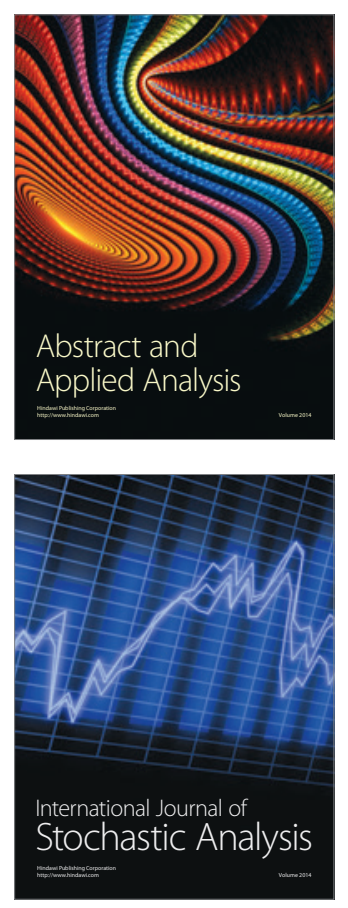

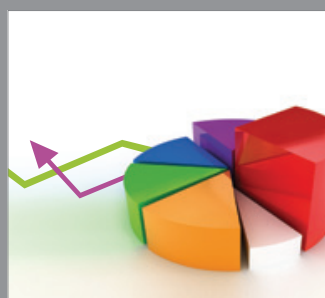

ournal of

Probability and Statistics

Promensencen
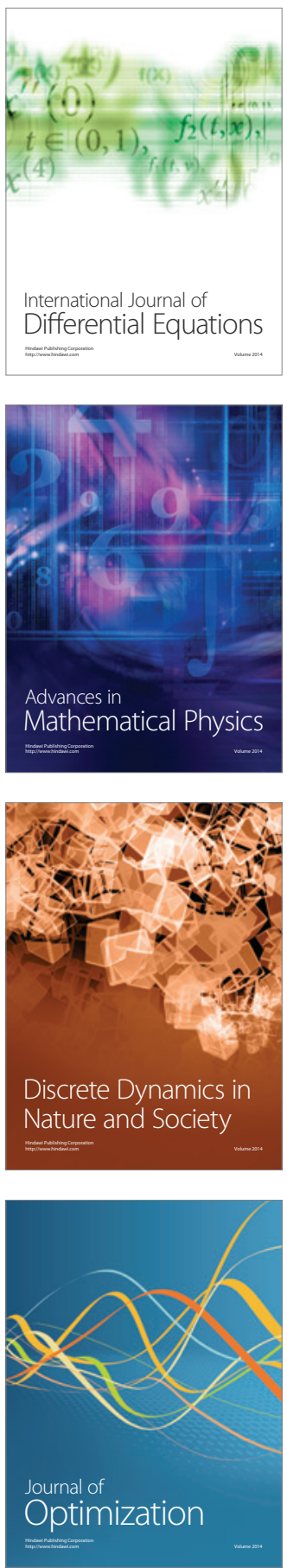